\title{
EFEKTIFITAS UNDANG-UNDANG NOMOR 23 TAHUN 2011 TENTANG PENGELOLAAN DAN PEMBERDAYAAN ZAKAT DALAM RANGKA MENGENTASKAN KEMISKINAN
}

\author{
Sugeng Riyadi \\ Magister Hukum Universitas Semarang
}

Tujuan dari penelitian ini adalah untuk menganalisis efektivitas Undang-undang Nomor 23 tahun 2011 tentang pengelolaan dan pemberdayaan zakat untuk mengurangi kemiskinan. Zakat adalah "maaliyah ijtima'iyah" agama, ibadah yang terkait dengan properti, yang memiliki posisi yang sangat penting untuk meningkatkan kesejahteraan masyarakat, jika dikelola dengan baik, dapat dipercaya, transparan Islamiyah yang sesuai dengan Syariah, baik pengumpulan dan distribusi. Diduga zakat tidak optimal karena pemerintah tidak memiliki kebijakan khusus untuk menjadikan zakat sebagai sumber penerimaan negara. Namun, jika amal telah menunjukkan fungsi yang luar biasa sebagai alat kemiskinan dan kesejahteraan rakyat, pemerintah dapat mulai melihat amal sebagai instrumen utama dalam perekonomian negara. Metode yang digunakan dalam penelitian ini adalah penelitian empiris yuridis. UU No. 13 tahun 2011 tentang pengelolaan dan distribusi zakat sampai saat ini tidak cocok untuk mengurangi kemiskinan. Karena hingga kini hanya profesi zakat yang dipertahankan dan hanya beberapa Unit Pemerintah Daerah saja di Jawa Tengah. Kemiskinan tidak hanya disebabkan oleh faktor alam saja, tetapi juga faktor pembangunan yang adil mempengaruhi masalah ini. Salah satu solusinya adalah memberdayakan amal berbasis komunitas. Dampaknya, mengentaskan kemiskinan berarti mengurangi penyebabnya, baik individu atau kelompok dalam masyarakat.

Kata kunci : Pemanfaatan; zakat; pengentasan kemiskinan 
$e-I S S N: 2621-4105$

\title{
EFFECTIVENESS OF LAW NUMBER 23 OF 2011 CONCERNING ZAKAT MANAGEMENT AND EMPOWERMENT IN ORDER TO REDUCE POVERTY
}

\author{
Sugeng Riyadi \\ Master of Law, University of Semarang
}

\begin{abstract}
The purpose of this study was to analyze the effectiveness of law number 23 of 2011 concerning management and empowerment of zakat in order to reduce poverty. Zakat is a religious "maaliyah ijtima'iyah", worship associated with the property, which has a position is very important to improve the welfare of the community, if properly managed, trustworthy, transparent Shari'a compliant Islamiyah, both collection and distribution. Suspected not optimal zakat because the government does not have specific policies to make zakat as a source of state revenues. However, if the charity has shown remarkable function as a tool of poverty and pensejahtera pengentas people, the government could begin to look to charity as a major instrument in the nation's economy. The purpose of this study was to determine the utilization of zakat is appropriate as the fight against poverty, and to determine the utilization of zakat in Central Java province Baznas strived for poverty alleviation.The method used in this research is juridical empirical research. UU No. 13 of 2011 concerning the management and distribution of zakat to date now is not suitable as reducing poverty. Because until now only zakat profession is maintained and only a couple of the Local Government Unit only in Central Java. Poverty is not just caused by natural factors alone, but also equitable development factors influence on this issue. One solution is to empower community-based charity. In effect, alleviating poverty is to alleviate the cause, either individuals or groups in society.
\end{abstract}

Keywords: Utilization of charity; zakat; poverty alleviation 


\section{A. PENDAHULUAN}

Dengan dicantumkannya Pasal-Pasal dalam UUD 1945 yang berhubungan dengan kebebasan menjalankan syari'at agama (Pasal 29) dan Pasal 34 UUD 1945 yang menyatakan bahwa fakir miskin dan anak-anak terlantar dipelihara oleh Negara. Kata "fakir miskin" yang dipergunakan dalam Pasal tersebut jelas menunjukkan kepada para mustahik yang berhak menerima zakat. ${ }^{1}$

Permasalahan kemiskinan di Indonesia sangat memprihatinkan, sudah lebih dari 70 tahun Indonesia merdeka dan lebih dari 15 tahun reformasi, tetapi masalah kemiskin-an menjadi masalah urgent dalam pembangunan Indonesia. Padahal, program pengentasan kemiskinan selalu tercantum dalam program pembangunan dari waktu ke waktu, dengan dana penanggulangan kemiskinan yang terus meningkat.

Sebagai umat muslim dan warga negara yang baik tentulah kewajiban membayar zakat dan pajak harus dipenuhi. Dengan adanya ketentuan bahwa zakat sebagai pengurang pajak, maka diharapkan kesadaran umat muslim untuk membayar zakat sehingga potensi zakat yang ada dapat terealisasi. Warga Negara Indonesia yang beragama islam berkewajiban mengeluarkan zakat sebagai realisasi pelaksanaan perintah agama dan berkewajiban pula membayar pajak sebagai realisasi ketaatan kepada pemerintah yang juga diwajibkan oleh agama. Zakat nantinya akan didistribusikan kepada 8 asnaf yang tercantum dalam Al Qur'an, sedangkan pajak akan masuk kepada APBN yang akan digunakan untuk kepentingan rakyat dan membangun fasilitas umum. ${ }^{2}$

\footnotetext{
${ }^{1}$ Abdul Aziz, Pendayagunaan Zakat Sebagai Upaya Pengentasan Kemiskinan, Jurnal Ius Constituendum Vol 1 No 1, Magister Hukum Universitas Semarang, 2017, Semarang, hlm 92. DOI: http://dx.doi.org/10.26623/jic.v1i2.552

${ }^{2}$ Agus Budi Yuwono, Kedudukan Potongan Pajak Pribadi Terhadap Zakat Yang Telah Dibayarkan, Jurnal USM Law Review Vol 1 No 1, Magister Hukum Universitas Semarang, 2018, Semarang, hlm 85.
} 
e-ISSN : 2621-4105

Permasalahan kemiskinan di-bicarakan tanpa berujung pada aksi nyata, oleh karena itu hal ini menarik banyak kalangan untuk dituntaskan dengan cara yang tepat dan cerdas. Setiap orang seolah bergairah untuk membicarakan tentang betapa miskinnya negeri ini, negeri yang konon elok rupawan, alamnya yang subur menghasilkan tetumbuhan yang menggiurkan, tetapi ternyata se-muanya itu tinggal sekedar cerita masa lalu. Kemiskinan tetap saja menjadi bagian yang belum terpisahkan dari bangsa yang indah ini. Yang lebih mengenas-kan adalah, penyakit akut kemiskinan itu ternyata telah bersarang di tubuh mayoritas ummat Islam, ia menyerang jasad ummat yang sesungguhnya memiliki nilai-nilai perjuangan untuk sukses dunia akhirat, tetapi kemudian harus mengalami sebuah "bencana" kemiskinan yang sangat dahsyat.

Islam sebagai agama yang universal yaitu sebuah agama tuntunan yang memberikan solusi bagi kemaslahatan ummatnya menawarkan solusi yang mampu mengatasi masalah tersebut yaitu dengan zakat. Ketentuan dalam Fiqih Islam, zakat itu wajib atas setiap Muslim yang merdeka yang telah memiliki satu nishab dari salah satu jenis harta yang wajib dikeluarkan zakatnya. ${ }^{3}$

Zakat mempunyai hubungan erat dengan ibadah lain seperti shalat sehingga kata zakat dalam Al-Qur'an seringkali disandingkan dengan kewajiban atau perintah shalat, misalnya di dalam Ayat, "wa aqiimush-shaalah wa aatuz-zakaah". Konsekuensi yuridisnya kewajiban zakat ini juga menjadi ukuran apakah seorang muslim itu disebut "taqwa" atau tidak, hal ini dapat dilihat dari ketaatan mem-bayar zakatnya, bahkan seseorang Muslim baru berhak menjadi "ikh-wan" atau "saudara" dalam dienul Islam jika telah membayarkan zakat. ${ }^{4}$

Yusuf Qardhawi mengemuka-kan pendapatnya tentang Zakat yaitu sebagai berikut: "Zakat me-rupakan ibadah amaliyah ijtima'iy-yah yang memiliki posisi

${ }^{3}$ Sayyid Sabiq, Fiqih Islam, Terj. M. Syaf, Jilid III, Bandung: Al-Maarif, 1990, hlm. 22.

4 A. Latief Muchtar, Pemahaman baru Tentang Harta yang Wajib Dizakatkan dan Implementasinya di Berbagai Negara, Makalah pada Seminar Zakat Profesi, Bandung: LPPM PUSKAJI UNISBA, 1993, hlm. 1. 
e-ISSN : 2621-4105

sangat penting, strategis dan menentu-kan". 5 Selanjutnya, guru besar ilmu syari'ah Universitas Al-Azhar, me-nyatakan bahwa "Zakat adalah rukun hartawi kemasyarakatan dari rukun Islam yang lima”. Zakat juga disebut ibadah sebagai "saudara kandung" shalat.

Didin Hafidhuddin memberi-kan pendapatnya tentang pengerti-an zakat yaitu sebagai berikut: “Zakat adalah ibadah maaliyah ijtima'iyah, ibadah yang berkaitan dengan harta yang memiliki kedu-dukan dan posisi yang sangat pen-ting dalam meningkatkan kesejah-teraan masyarakat, jika dikelola dengan baik, amanah, transparan dan sesuai dengan syariat Islami-yah baik pengambilannya maupun pendistribusiannya". ${ }^{6}$ Ia juga me-ngemukakan, bahwa manfaat za-kat, yaitu "Zakat mempunyai man-faat baik dilihat dari sisi ajaran Islam maupun dari sisi pembangunan kesejahteraan ummat. ${ }^{7}$

Gustian Djuanda mengemuka-kan pendapatnya tentang manfaat zakat, sebagai berikut: ${ }^{8}$

"Pada masa Rasulullah saw. di-kenal sebuah lembaga yang di-sebut Baitul Maal yang memiliki tugas dan fungsi mengelola ke-uangan negara. Sumber pemasukannya berasal dari dana zakat, infaq, kharaj (pajak bumi), jizyah (rampasan perang), fai' dan lain-lain. Sedangkan penggunaanya untuk asnaf mustahik (yang berhak menerima) yang telah ditentukan, seperti untuk kepentingan dakwah, pendidikan, pertahanan, kesejahte-raan sosial, pembuatan infrastruk-tur dan lain sebagainya".

Landasan Hukum Konstitusi di Negera Indonesia telah merumus-kan tentang kewajiban untuk men-jalankan perintah zakat ini ter-cantum dalam Pembukaan UUD 1945 Alinea ke-4 yang berbunyi sebagai berikut:

"Kemudian dari pada itu untuk membentuk suatu pemerintahan Negara Indonesia yang melindungi segenap bangsa Indonesia dan seluruh tumpah darah Indonesia dan untuk memajukan kesejahtera-an umum, mencerdaskan kehidup-an bangsa dan ikut melaksanakan ketertiban dunia yang berdasarkan kemerdekaan, perdamaian abadi dan keadilan sosial, maka di-susunlah Undang-Undang Dasar Negara Indonesia yang terbentuk dalam suatu susunan Negara Republik Indonesia yang berke-daulatan

\footnotetext{
${ }^{5}$ Yusuf Qardhawi, Al-Ibadah fil-Islam, Beirut: Mu'assasah Risalah, 1993, hlm.235.

${ }^{6}$ Didin Hafidhuddin, Islam Aplikatif, Jakarta: Gema Insani, 2003, hlm. 245.

${ }^{7}$ Didin Hafidhuddin, Zakat Dalam Perekonomian Modern, Jakarta: Gema Insani, 2002, hlm.1.

8 Gustian Djuanda, dkk, Pelaporan Zakat Pengurang Pajak Penghasilan, Jakarta: Rajawali Pers, 2006, hlm. 1.
} 
e-ISSN : 2621-4105

rakyat dengan berdasar-kan kepada Ketuhanan Yang Maha Esa, kemanusiaan yang adil dan beradab, persatuan Indonesia dan kerakyatan yang dipimpin oleh hikmat kebijaksanaan dalam per-musyawaratan/ perwakilan serta dengan mewujudkan suatu keadil-an sosial bagi seluruh rakyat Indonesia".9

Sebelum diterbitkan Undang-Undang Nomor 23 Tahun 2011, tentang pengelolaan zakat, pe-ngelolaan zakat di Indonesia tidak dilaksanakan secara professional, seperti dilakukan oleh perkumpulan orang, perseorangan tokoh umat Islam (alim ulama), atau pengurus/ takmir masjid/ musholla telah memberitahukan kegiatan pengelo-laan zakat. Pengelolaan yang ada masih sebatas sampingan, tidak meluas dan tidak tertanam kuat di masyarakat. ${ }^{10}$

Perlindungan dan jaminan menjalankan ibadah sesuai dengan agamanya dalam konstitusi Pasal 29 Ayat (2) UUD 1945 yang telah melahirkan UndangUndang Nomor 23 Tahun 2011 Tentang Penge-lolaan Zakat dianggap telah membawa "angin segar" dalam kehidup-an beragama di Indonesia terutama bagi Umat Islam. Dalam ketentuan umum Pasal 1 Point 7 Undang-Undang Nomor 23 Tahun 2011 disebutkan bahwa Badan Amil Zakat Nasional yang selanjutnya disebut Baznas, adalah lembaga yang melakukan pengelolaan zakat secara nasional.

Badan Amil Zakat Nasional (Baznas) merupakan bentukan masyarakat atau berada dibawah lembaga tertentu yang tidak ada kaitannya dengan pemerintah. Hal ini berguna untuk mengetahui apakah masya-rakat mempunyai respon positif untuk melaksanakan (membayar) zakat, dan bagaimana lembaga itu secara professional melaksanakan tugas pengelolaan zakat sebagai upaya pengentasan kemiskinan.

Ditengarai belum optimalnya fungsi zakat juga diakibatkan pemerintah tidak memiliki kebijakan khusus untuk menjadikan zakat sebagai salah satu sumber pemasukan negara, karena sumber pendapatan negara yang utama pada saat ini adalah pajak. Hal ini sangat disayangkan karena zakat adalah salah satu rukun Islam yang wajib dilaksanakan oleh umat Islam, dimana mayoritas dari penduduk yang ada di Indonesia adalah penduduk yang beragama Islam. Namun demikian, apabila zakat

9 Majelis Permusyawaratan Raktyat, Undang-Undang Dasar Negara Republik Indonesia Tahun 1945, Jakarta: Sekretariat Jenderal MPR RI, 2015, hlm. 3.

${ }^{10}$ T.M. Hasbi Ash Shiddieqiy, Pedoman Zakat, Semarang: Pustaka Rizki Putra, 1999, hlm. 11. 
$e-I S S N: 2621-4105$

telah memperlihatkan fungsi-nya yang luar biasa sebagai alat pengentas kemiskinan dan pen-sejahtera umat, bisa saja pemerin-tah mulai melirik zakat sebagai instrument utama dalam pereko-nomian bangsa.

Salah satu kunci keberhasilan pemberdayaan Ziswaf ini terletak dalam manejemen (pengelolan-nya). Untuk menjalankan tugas dan fungsi zakat di era modern ini mutlak harus dikembangkan men-jadi satu organisasi manajemen Ziswaf yang handal, salah satu diantaranya yaitu Baznas. Efekti-fitasnya perlu dipertanyakan, karena masalah kemiskinan umat Islam Indonesia khususnya Provinsi Jawa Tengah sampai saat ini belum dapat dipecahkan.

\section{B. TELAAH PUSTAKA}

Zakat sebagai suatu amalan mempunyai dua fungsi yaitu seba-gai ibadah bagi muzzaki dan juga sebagai sumber utama pendapatan Negara. Dalam pengelolaan zakat pada zaman kepemimimpinannya, Nabi sendiri yang turun tangan memberikan contoh dan petunjuk operasionalnya. ${ }^{11}$ Prosedur pe-ngumpulan dan pendistribusian zakat diluar kota Madinah, Nabi mengutus petugas untuk mengum-pulkan dan menyalurkan zakat. Diantara petugas itu adalah Mu'adz bin Jabal untuk memungut dan mendistribusikan zakat dari dan untuk penduduk Yaman. Rasulullah saw. mengangkat pegawai zakat (amilin) antara lain Ibnu Lutabiyah, Abu Mas'ud, Abu Jahm, Ubah bin Amir, Dahhaq, Ibnu Qais dan Ubadah bin as-Samit, untuk mengumpulkan zakat dan membagi-nya kepada yang berhak. ${ }^{12}$

Lembaga-lembaga Negara yang bertugas menerima, meng-himpun dan mendistribusikan zakat tersebut disebut dengan "Baitul Mal", yang dibentuk dengan tujuan sebagai sarana terciptanya tujuan Negara dan pemerintahan serta untuk kesejahteraan kaum muslimin. ${ }^{13}$

${ }^{11}$ Abdurrahman Qadir, Zakat Dalam Dimensi Mahdhah dan Sosial, Jakarta: Grafindo Persada, tth., hlm. 88 .

12 Sjehul Hadi Permono, Pemerintah Indonesia Sebagai Pengelola Zakat, Jakarta: Pustaka Firdaus, hlm. 37.

13 Abdul Aziz Dahlan, et Al., Ensiklopedi Hukum Islam, Jilid 1, Jakarta: Ichtiar baru Van Hoeve, hlm. 187. 
$e-I S S N: 2621-4105$

Pengelolaan yang telah di-lakukan Rasullullah ini dilanjutkan oleh para sahabat sebagai suatu amanah yang diemban untuk men-capai kesejahteraan umat yang menjadi tujuan agama Islam. Abu Bakar merupakan salah satu sahabat yang dapat menjaga ke-utuhan dan kesatuan bangsa Arab serta mempertahankan lembagalembaga syari'at yang berlaku sejak Nabi saw. tercatat beberapa tindakan yang dilakukan oleh Abu Bakar pada masa kekhalifahannya untuk mempertahankan lembaga zakat dalam perlawanan yang dilakukan oleh bangsa Arab bagi yang tidak membayar zakat salah satunya dengan menerapkan hukuman mati bagi orang yang menolak membayar zakat. ${ }^{14}$

Pada masa kekhalifahan Umar Ibn al-Khatab tidak segan-segan mengeluarkan ancaman dan tindakan tegas bagi petugas yang lalai atau menyalahgunakan harta zakat. Pengelolaan wilayah yang semakin luas dengan persoalan yang semakin kompleks, Umar membenahi struktur pemerintahan-nya dengan membentuk beberapa lembaga baru yang bersifat eksekutif operasional. Diantara lembaga baru yang dibentuk Umar adalah Baitul Mal yang berfungsi untuk mengelola sumbersumber keuangan termasuk zakat. ${ }^{15}$

Pada zaman kekhalifahan Utsman bin Affan, pengumpulan zakat tidak lagi dipusatkan pada khalifah, karena bagi khalifah Utsman, urusan zakat merupakan urusan yang penting, untuk itu beliau mengangkat pejabat khusus untuk menangani hal tersebut, yaitu Zaid bin Tsabit.

Pada masa pemerintahan khalifah Ali bin Abi Tahlib yang dibai'at setelah lima hari terbunuh-nya khalifah Utsman bin Affan, persoalan zakat menjadi sangat kompleks karena terjadinya gejolak dalam masalah politik serta per-pecahan dalam masyarakat. Dengan kecerdasannya, Ali bin Abi Thalib mempunyai sudut pandang lain dalam menetapkan persamaan jumlah dalam pembagian harta kekayaan, beliau

${ }^{14}$ Saidus Sahar, Azas-Azas Hukum Islam, Bandung: Alumni, tt., hlm. 90.

${ }^{15}$ Abudin Nata, Mengenal Zakat, Infaq dan Shadaqah, Jakarta: Bazis, tth., hlm. 91. 
$e-I S S N: 2621-4105$

menolak untuk membedakan status masyarakat dalam pembagian harta dari Baitul Mal. ${ }^{16}$

Periode Daulah Bani Umay-yah yang berlangsung selama ham-pir sembilan puluh tahun (41-127 H) tampil salah seorang khalifahnya yang terkenal, yaitu Umar bin Abdul Aziz (99-101 H). Beliau terkenal dengan kebijakan dan keadilan serta keberhasilannya dalam me-majukan dan mensejahterakan ma-syarakat, termasuk keberhasilan dalam penanganan zakat, sehingga zakat yang terkumpul melimpah ruah dalam "Baitul Mal" sampai menimbulkan kesulitan bagi petu-gas amil zakat mencari golongan fakir miskin yang membutuhkan harta zakat tersebut.

Menurut Yusuf Qardhawi, pada masa Umar bin Abdul Aziz menjadi khalifah, Negara berada dalam keadaan adil dan makmur serta kemiskinan pun sirna. Pada masa inilah Yahya bin Said diutus oleh khalifah untuk membawa zakat ke Afrika. Berhari-hari Yahya mencari fakir miskin yang berhak diberi zakat, tetapi usahanya sia-sia kerena tidak menemukan orang-orang tersebut hal ini dikarenakan khalifah telah memberikan kemak-muran kepada rakyatnya, maka harta zakat itu dijadikan oleh Yahya untuk membeli budak agar dapat membebaskan mereka. ${ }^{17}$

Sejalan dengan perjuangan Bangsa Indonesia menentang pen-jajahan Barat dahulupun, zakat terutama bagian sabilillahnya me-rupakan sumber dana perjuangan. ${ }^{18}$ Namun ketika satu persatu tanah air kita dikuasai oleh penjajah Belanda, pemerintah Kolonial me-ngeluarkan Bijblad Nomor 1892 tanggal 4 Agustus 1893 yang berisi kebijak-sanaan pemerintah K.N. Sofyan Kolonial mengenai zakat. ${ }^{19}$

Dicantumkannya Pasal-Pasal dalam UUD 1945 yang berhubung-an dengan kebebasan menjalan-kan syari'at agama (Pasal 29) dan Pasal 34 UUD 1945 yang me-nyatakan bahwa fakir miskin dan anak-anak terlantar dipelihara oleh Negara.

\footnotetext{
${ }^{16}$ Muhammad, Zakat Profesi Wacana Pemikiran Dalam Fiqih Kontemporer, Jakarta: Penerbit Salemba Diniyah, hlm. 35.

17 Yusuf Qardhawi, Syari'at Islam di Tantang Zaman, terj. Abu Zaky, Surabaya: Pustaka Progressif, hlm. 30.

${ }^{18}$ K.N. Sofyan Hasan, Pengantar Hukum Zakat dan Wakaf, Surabaya: Al-Ikhlas, hlm.13. hlm. 250 .

19 Muhammad Daud Ali, Lembaga-Lembaga Islam di Indonesia, Jakarta: Grafindo Persada,
} 
e-ISSN : 2621-4105

Kata "fakir miskin" yang dipergunakan dalam Pasal tersebut jelas menunjukkan kepada para mustahik yang berhak menerima zakat.

Hal ini merupakan perhatian Pemerintah terhadap lembaga zakat ini secara kualitatif mulai meningkat pada tahun 1968. Pemerintah mengeluarkan Peratur-an Menteri Agama Nomor 4 tentang pembentukan Badan Amil Zakat dan Nomor 5 Tahun 1968 tentang pembentukan Baitul Mal di tingkat pusat, provinsi dan kabupaten/ kota. Setahun sebelumnya, yakni pada Tahun 1967, Pemerintah telah menyiapkan RUU Zakat yang akan dimajukan kepada DPR untuk disahkan menjadi Undang-Undang. ${ }^{20}$

Dengan adanya perhatian yang begitu besar oleh Pemerintah dalam hal Zakat ini, maka didiri-kanlah Badan Amil Zakat dengan dilatarbelakangi oleh kon-disi nasional yang menuntut semua komponen bangsa untuk ikut ber-partisipasi dalam pembangunan. Demikian pula ummat Islam di Indonesia yang merupakan salah satu harapan bangsa, wajib pula ikut serta mengisi dan melanjutkan usaha pembangunan itu. Bahkan sebagai komponen yang dominan dan potensial, ummat Islam tidak hanya dituntut kuantitasnya me-lainkan juga subtansi ajaran Islam yang secara menyeluruh untuk membangun bangsanya. ${ }^{21}$

Pengelolaan zakat di Indo-nesia pada saat ini telah diatur ber-dasarkan Undang-Undang Nomor 23 Tahun 2011 dikuatkan dengan PP Nomor 14 Tahun 2014, tentang Pelaksanan Undang-Undang No. 23 Tahun 2011, tentang Pengelola-an Zakat dan KMA 118 Tahun 2014 Pembentukan BAZNAS Provinsi, Undang-Undang tersebut telah mendorong upaya pembentukan lembaga pengelola zakat yang amanah, kuat dan dipercaya oleh masyarakat.

Tujuan pembangunan Nasio-nal Negara Republik Indonesia adalah identik dengan sasaran dan tujuan zakat. Konsep zakat ada per-sesuainnya dengan sila dalam Pancasila, Undang-Undang Dasar 1945 Pasal 27 Ayat (2), Pasal 29 dan Pasal 34. Pengurusan zakat oleh Pemerintah merupakan kon-sepsi yang integral dalam merea-

${ }^{20}$ Muhammad Daud Ali, Sistem Ekonomi Islam, Zakat dan Wakaf, Jakarta: UI Press, hlm.39.

${ }^{21}$ A. Djazuli, Yodi Jon Wari, Lembaga-Lembaga Perekonomian Ummat: Sebuah Pengenalan, Jakarta: Raja Grafindo Persada, hlm. 37. 
e-ISSN : 2621-4105

lisasikan Pancasila khusus-nya sila Keadilan Sosial dan Pasal 34 Undang-Undang Dasar 1945 yang berbunyi "Fakir miskin dan anak terlantar dipelihara oleh negara". Pemerintah wajib menyelengg-arakan berbagai untuk mencapai masyarakat yang adil dan makmur menuju kesejahteraan rakyat lahir batin.

Seluruh konsep pengelolaan zakat tersebut diatur dalam Pasal 2 UndangUndang Nomor 23 Tahun 2011 yang menyebutkan bahwa pengelolaan zakat berasaskan: syariat Islam, amanah, kemanfa-atan, keadilan, kepastian hukum, terintegrasi, dan akuntabilitas. Selanjutnya Pasal 3 merumuskan bahwa pengelolaan zakat bertujuan untuk meningkatkan efektivitas dan efisiensi pelayanan dalam pengelo-laan zakat; dan meningkatkan manfaat zakat untuk mewujudkan kesejahteraan masyarakat dan penanggulangan kemiskinan.

\section{METODE PENELITIAN}

Metode adalah proses, prin-sip-prinsip dan tata cara memecah-kan suatu masalah, sedangkan penelitian adalah pemeriksaan se-cara hati-hati, tekun dan tuntas terhadap suatu gejala untuk me-nambah pengetahuan manusia, maka metode penelitian dapat diartikan sebagai proses, prinsip-prinsip dan tata cara untuk memecahkan masalah yang dihadapi dalam melakukan penelitian. ${ }^{22}$

Metode yang digunakan dalam penelitian ini adalah penelitian yuridis empiris, yaitu penelitian yang mengacu kepada norma-norma dan asas-asas hukum yang terdapat dalam peraturan perundang-undangan dan putusan penga-dilan dan disesuaikan dengan kondisi yang sebenarnya. Ronald Dworkin menyebut metode penelitian tersebut juga sebagai penelitian doktrinal (doctrinal research), yaitu suatu penelitian yang menganalisis baik hukum sebagai "law as it written in the book", maupun hukum sebagai "law as it is decided by the judge through judicial process". 23

Ketiga, sifat dasar data yang akan dianalisis dalam penelitian adalah bersifat me-nyeluruh dan merupakan suatu kesatuan yang integral, dimana hal itu

${ }^{22}$ Soerjono Soekanto, Pengantar Penelitian Hukum, Jakarta: UI Press, 1986, hlm. 6.

23 Anselmus Strauss, dan Juliat Corbin, Basic of Qualitative Research, Grounded Theory Procedure and Technique, Newbury, Park London, New Delhi: Sage Publication, 1979, hlm. 7. 
$e-I S S N: 2621-4105$

menunjukkan adanya ke-anekaragaman data serta me-merlukan informasi yang mendalam (indepth information). ${ }^{24}$

Penelitian ini juga ber-upaya mencari hubungan yang harmonis dari konsepkonsep yang ditemukan dalam bahan-bahan hukum primer dan skunder dengan menggunakan teori atau doktrin-doktrin hukum, ${ }^{25}$ terkait pendayaguna-an zakat sebagai upaya pe-ngentasan kemiskinan.

Secara umum jenis data yang diperlukan dalam suatu penelitian hukum terarah pada penelitian data sekunder dan primer.

a. Bahan hukum primer adalah bahan hukum yang mem-punyai kekuatan mengikat dalam masyarakat. Bahan hukum sekunder adalah ba-han hukum yang dapat menginformasikan sumber hukum primer, sedangkan bahan hukum tersier adalah bahan yang memberikan petunjuk atau penjelasan mengenai sumber hukum primer dan sekunder. ${ }^{26}$

b. Bahan hukum tersier, yaitu bahan hukum penunjang yang memberi petunjuk dan penjelasan terhadap bahan hukum primer dan bahan hukum sekunder, seperti kamus umum, majalah dan jurnal ilmiah, surat kabar, artikel bebas dari internet, dan majalah ${ }^{27}$ juga menjadi tambahan bahan bagi penulisan tesis ini sepanjang memuat informasi yang relevan dengan penelitian ini.

\section{PEMBAHASAN}

Kemiskinan dapat digolongkan dalam kemiskinan struktural, kemiskinan kultural dan kemiskinan natural. Kemiskinan struktural di-sebabkan oleh kondisi struktur per-ekonomian yang timpang dalam masyarakat, baik karena kebijakan ekonomi pemerintah, penguasaan faktor-faktor produksi oleh segelintir orang,

${ }^{24}$ William J. Filstead, Qualitative Methods: A Needed Perspective in Evaluation Reseaarch, dalam Thomas D. Cook dan Charles S. Reichardt, ed, Qualitative and Quantitative Methods in Evalution Research, London: Sage Publications, 1979, hlm. 38.

${ }^{25}$ Chai Podhisita, et al, Theoritical Terminological, and Philosophical Issues in Qualitative Research, Qualitative Research Methods, hlm. 7.

26 Sri Mamudji et al. Metode Penelitian dan Penulisan Hukum, Jakarta: Badan Penerbit Fakultas Hukum Universitas Indonesia, 2005, hlm. 31.

27 Soerjono Soekamto dan Sri Mamudji, Penelitian Hukum Normatif Suatu Tinjauan Singkat, Jakarta: Rajawali Press, 1990, hlm. 14-15. 
$e-I S S N: 2621-4105$

monopoli, kolusi antara pengusaha dan pejabat dan lain-lainnya. Intinya kemiskinan struk-tural ini terjadi karena faktor-faktor buatan manusia. Adapun kemiskin-an kultural muncul karena faktor budaya atau mental masyarakat yang mendorong orang hidup miskin, seperti perilaku malas bekerja, rendahnya kreativitas dan tidak ada keinginan hidup lebih maju. Sedangkan kemiskinan natu-ral adalah kemiskinan yang terjadi secara alami, antara lain yang disebabkan oleh faktor rendahnya kualitas sumber daya manusia dan terbatasnya sumber daya alam. Dari ketiga katagori kemiskinan tersebut, pada dasarnya kemis-kinan berpangkal pada masalah distribusi kekayaan yang timpang dan tidak adil. Karena itu Islam menekankan pengaturan distribusi ekonomi yang adil agar ketimpangan di dalam masyarakat dapat dihilangkan.

Berdasarkan uraian tersebut di atas, bahwa pelaksanaan UU Nomor 23 Tahun 2011, tentang Pengelolaan Zakat masih banyak hambatan yang dihadapi. Adapun kendala yang dihadapinya antara lain:

a. Realita yang ada masih banyak muzakki yang masih enggan untuk membayar zakat, ter-utama para orang-orang kaya masih banyak yang enggan membayar zakat atau hanya membayar sebagian kewajiban-nya, yaitu sebatas zakat fitrah pada hari raya idul fitri saja;

b. Kepercayaan masyarakat ( $m u-z a k k i)$ kurang terhadap Baznas dalam transparansi pengelolaan zakat;

c. Sosialisasi kepada masyarakat masih kurang optimal.

Solusi yang harus dilakukan, meliputi:

a. Melakukan pembinaan pencer-dasan muzakki. Disadari ber-sama bahwa para Muzakki belum banyak memahami ten-tang hakikat penunaian zakat. Selama ini, zakat hanya di-pahami sebatas zakat fitrah, sehingga potensi ketersediaan zakat maal, yang jumlahnya mayoritas belum tergarap. Instrumen formal dari regulasi zakat yang mendukung. Lang-kah yang paling memungkinkan adalah dilakukannya regulasi tentang kewajiban zakat bagi Muzakki;

b. Penguatan kepada amil zakat untuk selalu bersikap jujur dan professional. 
e-ISSN : 2621-4105

Lembaga zakat ini sebenarnya ini sama halnya dengan perbankan yaitu bermodalkan kepercayaan. Jadi, bagaimana membuat masyara-kat bisa percaya pada lembaga dengan berbagai tindakan dan kegiataan yang ada. Sehingga, masyarakat dapat melihat fakta yang selama ini telah dilakukan oleh lembaga. Dengan hal itulah maka masyarakat akan ter-gugah untuk menyalurkan zakatnya kepada lembaga;

c. Mensinergikan dan saling kerja-sama antara lapisan masyara-kat, pemerintah, tokoh agama dan juga para amil zakat. Dengan adanya hubungan itu maka akan terasa mudah untuk mendistribusikan zakat ke ber-bagai mustahik. Bentuknya adalah lapisan masyarakat ikut mensupport adanya lembaga zakat dengan menyalurkan dananya ke lembaga tesebut.

Kemiskinan bukan hanya disebabkan oleh faktor alamiah saja, namun faktor pemerataan pembangunan juga memberikan pengaruh terhadap masalah ini. Salah satu solusi yang ditawarkan oleh ekonomi Islam untuk menyele-saikan masalah ini, yaitu dengan pemberdayaan masyarakat ber-basis kepada zakat.

Mengentaskan kemiskinan adalah dengan mengentaskan pe-nyebabnya. Agar seseorang dapat menunaikan zakatnya untuk me-ngentaskan kemiskinan, maka perlu diketahui penyebab kemiskin-an terhadapa individu atau kemis-kinan yang terjadi pada satu kelom-pok masyarakat. Setiap penyebab kemiskinan diobati dengan formula yang berbeda-beda, meliputi:

a. Kemiskinan yang disebabkan oleh kelemahan fisik yang menjadi penghalang dirinya dalam mendapatkan penghasil-an yang besar.

b. Kemiskinan yang disebabkan oleh ketidakmampuan untuk mencari pekerjaan, karena di-tutupnya pintu-pintu yang halal sesuai dengan keadaan para fakir miskin tersebut.

c. Kemiskinan yang disebabkan oleh kurangnya pendapatan yang ia peroleh untuk men-cukupi kebutuhan hidupnya, se-kalipun ia mempunyai peng-hasilan tetap.

Keberhasilan zakat tergantung kepada pendayagunaan dan pe-manfaatannya. Walaupun seorang wajib zakat (muzakki) mengetahui dan mampu memperkirakan 
e-ISSN : 2621-4105

jumlah zakat yang akan ia keluarkan, tidak dibenarkan ia menyerahkannya kepada sembarang orang yang ia sukai. Zakat harus diberikan kepada yang berhak (mustahik) yang sudah ditentukan menurut agama. Penyerahan yang benar adalah melalui badan amil zakat. Walaupun demikian, kepada badan amil zakat manapun tetap terpikul kewajiban untuk mengefektifkan pendayagunaannya. Pendayaguna-an yang efektif ialah efektif man-faatnya (sesuai dengan tujuan) dan jatuh pada yang berhak (sesuai dengan nas) secara tepat guna.

\section{E. PENUTUP}

Bahwa UU Nomor 23 tahun 2011 tentang Pengelolaan dan Pemberdayaan Zakat jika dilihat dalam perspektif sarana pengen-tasan kemiskinan belum menampakkan sifnifikasi yang masimal. Hal ini disebabkan bebapa masalah pokok dalam ketentuan UU tersebut yang masih menititik-tekankan peranan kelembagaan yang bersifat formal dalam upaya pengetasan kemiskinan disban-dingkan penguatan cultural (kebu-dayaan masyarakat) dalam mewu-judkan upaya untuk mengenaskan kemiskinan disisi lain persoalan yang mendasar terkait keberlakuan UU Nomor 23 Tahun 2011 tentang Pengelolaan dan Pemberdayaan Zakat misih melihat secara prag-matis dalam dalam melihat per-soalan-persoalan tentang peng-aturan zakat dalam UU tersebut hanya dilihat dalam perspektif pengentasan kemiskinan bukan sebagai wujud pemberdayaan masyarakat dalam penanggulangan kemiskinan.

Bahwa keberlakuan UU Nomor 23 Tahun 2011 tentang Pengelolaan dan Pemberdayaan Zakat masih belum dianggap efektif de-ngan melihat beberapa masalah yang dirumuskan dalam berbagai jawaban sesuai dengan pertanyaan rumusan masalah masalah di atas. Upaya untuk melakukan pening-katan atau mengefektifkan UU Nomor 23 Tahun 2011 tentang Pengelolaan dan Pemberdayaan Zakat tentunya sangat dibutuhkan. Salah satu upaya yang dilakukan adalah memberikan perluasan-perluasan atau makna-makna atau tafsir-tafsir berkaitan dengan ke-terlibatan masyarakat dalam pem-berdayaan zakat. Hal tersebut berdasarkan salah satu teori ten-tang sistem hukum yang dapat berjalan tidak hanya didukung oleh struktur dan substansi akan tetapi harus didukung oleh kultur budaya 
e-ISSN : 2621-4105

dan keterlibatan masyarakat. Disamping itu upaya untuk mening-katkan efektifitas UU Nomor 23 Tahun 2011 adalah dengan jalan menyerahkan bagi pelaksana zakat untuk lebih menekankan upaya pemberdayaan ketimbang pemberi-an zakat yang diatur jelas dalam UU Nomor 23 Tahun 2011 tentang Pengelolaan dan Pemberdayaan Zakat.

\section{DAFTAR PUSTAKA}

\section{BUKU}

Al-Qur'an dan Terjemahnya, T.M. Hasbi Ashshiddiqi, (alm), dkk., Cet. IV, Yayasan Pe-nyelenggara Penterjemah Al-Qur'an, Departemen Agama RI., Jakarta: Pelita III, 1983.

A. Latief Muchtar, Pemahaman baru Tentang Harta yang Wajib Dizakatkan dan Implementasinya di Berbagai Negara, Makalah pada Seminar Zakat Profesi, Bandung: LPPM PUSKAJI UNISBA, 1993.

Anselmus Strauss, dan Juliat Cor-bin, Basic of Qualitative Research, Grounded Theory Procedure and Tech-nique, Newbury, Park London, New Delhi: Sage Publication, 1979.

Didin Hafidhuddin, Islam Aplikatif, Jakarta: Gema Insani, 2003.

Gustian Djuanda, dkk, Pelaporan Zakat Pengurang Pajak Penghasilan, Jakarta: Raja-wali Pers, 2006.

Hans Kelsen, General Theory of law and state, diterjamah-kan oleh Rasisul Muttaqin, Bandung: Nusa Media, 2011. 
$e-I S S N: 2621-4105$

HR. Otje Salman S dan Anton F Sutanto, Teori Hukum, Bandung: Refika Aditama, 2005.

Maria Alfons, Implentasi Perlin-dungan Indikasi Geografis Atas Produk-Produk Ma-syarakat Lokal Dalam Prespektif Hak Kekayaan Intelektual, Malang: Univer-sitas Brawijaya, 2010.

Marwan Mas, Pengantar Ilmu Hukum, Jakarta: Ghalia Indonesia, 2004.

Phillipus M. Hadjon, Perlindungan Hukum bagi Rakyat Indonesia, Surabaya: Bina Ilmu, 1987.

Satijipto Raharjo, llmu Hukum, Bandung: Citra Aditya Bakti, 2000.

Sayyid Sabiq, Fiqih Islam, Terj. M. Syaf, Jilid III, Bandung: Al-Maarif, 1990.

Soerjono Soekamto dan Sri Mamudji, Penelitian Hukum Normatif Suatu Tinjauan Singkat, Jakarta: Rajawali Press, 1990.

Sri Mamudji et al. Metode Penelitian dan Penulisan Hukum, Jakarta: Badan Penerbit Fakultas Hukum Universitas Indonesia, 2005.

Sudarsono, Kamus Hukum Edisi Baru, Penerbit Rineka Cipta, Cetakan kelima, Jakarta: 2007.

Sudikno Mertokusumo, Perkem-bangan Teori Dalam Ilmu Hukum, Jakarta: Rajagrafindo Persada, 2010.

-----,----, Penemuan Hukum se-buah Pengantar, Yogyakar-ta: Liberty, 2009.

Sulistyowati Irianto \& Shidarta, Metode Penelitian Hukum Konstelasi dan Reflekasi, Jakarta: Pustaka Obor Indonesia, 2013.

Suteki, Desain Hukum di Ruang Sosial, Thafa Media, Yogyakarta, 2013.

T.M. Hasbi Ash Shiddieqiy, Pe-doman Zakat, Semarang: Pustaka Rizki Putra, 1999. Yusuf Qardhawi, Al-Ibadah fil-Islam, Beirut: Mu'assasah Risalah, 1993.

\section{JURNAL}

Abdul Aziz, Pendayagunaan Zakat Sebagai Upaya Pengentasan Kemiskinan, Jurnal Ius Constituendum Vol 1 No 1, Magister Hukum Universitas Semarang, 2017, Semarang. http://dx.doi.org/10.26623/jic.v1i2.552

Agus Budi Yuwono, Kedudukan Potongan Pajak Pribadi Terhadap Zakat Yang Telah Dibayarkan, Jurnal USM Law Review Vol 1 No 1, Magister Hukum Universitas Semarang, 2018, Semarang. 